\title{
Demand and the impact of leading questions on eyewitness testimony
}

\author{
HOWARD I. WEINBERG, JOHN WADSWORTH, and ROBERT S. BARON \\ University of Iowa, Iowa City, Iowa 52242
}

\begin{abstract}
Recently, Loftus and her associates have demonstrated that the ability of subjects to respond accurately to questioning about an event they witnessed can be systematically imparied by the interposition of misleading questions between exposure to the event and assessment of accuracy. One explanation for this low eyewitness accuracy is that it is due to demand characteristics created by the misleading questions. The present study addresses this issue using a modification of the paradigm developed by Loftus, Miller, and Burns (1978). The results indicate that even when the final accuracy test does not easily allow subjects to accede to demand pressure, significant impairment of eyewitness accuracy is still obtained. Since this lowered accuracy does not seem due to simple compliance to demand pressure, it suggests that misleading questions do in fact interfere with subsequent eyewitness accuracy.
\end{abstract}

According to E. F. Loftus, questions that are subtly loaded with implications regarding an event can alter a witness's memories for that event (Loftus, 1974, 1975a, 1975b, 1977, 1978, 1979; Loftus, Altman, \& Geballe, 1975; Loftus \& Loftus, 1980; Loftus, Miller, \& Burns, 1978; Loftus \& Palmer, 1974; Loftus \& Zanni, 1975).

Most of this work uses the same research strategy: Subjects are shown a film, videotape, or slide show depicting a series of events-most often, an automobile accident. Immediately afterward, subjects fill out an experimental questionnaire concerning the events they have just witnessed. For experimental subjects, one question on this questionnaire contains a false assumption concerning the event just witnessed. Control subjects receive a similar question that does not contain the assumption. After a period of time ( $20 \mathrm{~min}$ to 1 week), the ability of subjects to remember and/or make judgments about the original event is assessed.

For example, Loftus and Palmer (1974) asked a control group of subjects (via questionnaire), "How fast were the cars going when they contacted?" Other groups of subjects were asked similar questions in which the verb "contacted" was replaced by "smashed," "collided," "bumped," or "hit." Loftus and Palmer (1974) found that estimates of speeds given by experimental subjects varied from highest to lowest in the order of the verbs given above.

In this and other publications (Loftus et al., 1975; Loftus \& Zanni, 1975), Loftus and her colleagues have demonstrated that, at a minimum, postevent questioning can have a significant effect on subsequent reporting. Loftus and Loftus (1980, p. 418) suggest that the rea-

This study formed a portion of the first author's master's thesis. Requests for reprints should be sent to Robert Baron, Department of Psychology, University of Iowa, Iowa City, Iowa 52242 . son for this effect may be that eyewitness memory is actually changed by postevent questioning. An alternative possibility is that subject reporting is influenced by the demand characteristics of the experimental situation.

That is, it seems possible that when subjects are asked questions such as "How fast were the cars going when they smashed?", they infer that the person asking the question already feels the cars were moving at relatively high speeds. If so, many subjects will deduce that giving a "relatively high-speed" answer to this question is the best means of (1) being viewed as a perceptive observer by the questioner and (2) obtaining social rewards directly from the questioner as a result of confirming his/her beliefs. In short, there are several potent demand characteristics in the paradigm favored by Loftus and her associates that may lead subjects to give inaccurate eyewitness reports despite still having access to the original information.

On the other hand, if subjects do infer a questioner's beliefs on the basis of his questions (as discussed above), these inferences could affect subjects' intemalized beliefs about an event, as Loftus and Loftus (1980) argue. This could take place through direct social influence mechanisms (e.g., lowering subject's confidence in his original perceptions, etc.; Sherif, 1935). As a result, nondemand explanations for the reporting errors found by Loftus are also quite plausible. ${ }^{1}$

Loftus et al. (1978) used a debriefing questionnaire to assess the demand explanation. Loftus et al. found that, as expected, subjects exposed to misleading questions were less likely than others to identify a traffic sign they had actually seen previously in a slide show and were more likely to identify the traffic sign suggested by the misleading question. Loftus et al. argued that subjects who were influenced by the demand characteristics of the situation would admit on a debriefing questionnaire that they reported one type of sign when in fact 
they had seen another. Unfortunately, this essentially asks subjects to admit to dishonesty. Not surprisingly, few subjects admitted having seen one stimulus and reported another. However, this can hardly be deemed strong evidence against a demand explanation.

In the present experiment, we explored the demand explanation with a different strategy. Basically, we modified the three-stage procedure of Loftus et al. (1978). In Stage 1, subjects view several slides, including one in which a car is seen stopped at a yellow yield sign. In Stage 2, subjects answer a question that misleadingly refers to a stop sign or accurately refers to a yield sign (e.g., "Did the car come to a complete halt at the

sign?”). Stage 3 occurs after a 20 -min filler task. At that point, each subject takes one of two forced-choice recognition tests (stop-yield/yield-yield). In these recognition tests, subjects are shown two slides and asked to choose the one they had seen previously (in Stage 1). In the stop-yield condition, one slide depicts a car stopped by a yield sign and the other slide depicts it stopped at a stop sign, as in Lofuts et al. (1978). The experiment as described thus far is equivalent to Experiment 1 of Loftus et al. (1978). ${ }^{2}$ Both studies employ fairly similar (although not identical) slide presentations, questions about stop and yield signs, and a 20-min delay between Stages 2 and 3. The chief modification to Loftus et al. (1978) is the addition of a yield-yield forced-choice cell. This condition is equivalent to the stop-yield condition, except that in Stage 3 subjects must choose between the original slide depicting a yellow yield sign and a similar slide depicting a red yield sign. (Both the red and the yellow yield signs are commonly used on highways in the state in which the research was conducted.)

It is predicted that subjects who received the misleading (stop sign) question (in Stage 2) will be more likely to pick the stop sign when faced with the stop-yield choice (in Stage 3) than subjects who received the nonmisleading (yield sign) question. This is the same prediction confirmed by Loftus et al. (1978). Failure to produce this finding would indicate that there was some critical difference between their procedures and our own. Success in obtaining this result, on the other hand, might be attributable to alteration of memory or to the demand characteristics of the experimental situation. That is, the misleading (stop sign) question in Stage 2 may create implicit demand for subjects to report seeing a stop sign. Offering subjects a stop-yield choice in Stage 3 should subtly strengthen this demand by implying that the "stop sign choice" is a reasonable response. The importance of this demand, however, can be assessed by examining the responses of those subjects who receive misleading questions (in Stage 2) and who must make a yield-yield choice in Stage 3. These subjects see a yield sign in Stage 1 and are asked questions about a stop sign in Stage 2 . While this may create an implicit demand to say there was a stop sign, these subjects have no way to comply with that demand on their final choice (in Stage 3), on which they must choose between a yellow yield sign or a red yield sign. As a result, if these subjects actually still have access to their original representation, they should be as accurate at correctly identifying the yellow yield sign as subjects who received a subsequent question that was consistent with the original perception.

However, if misleading questioning has an effect above and beyond that induced by demand, such as altering original memory traces, then subjects exposed to such questions should be less accurate than subjects who receive nonmisleading questions, even when faced with the yield-yield task, in which demand is a less attractive explanation. We, of course, expect the overall rate of accurate identification to be lower in the yield-yield cells than in the stop-yield cells. This prediction is based on the notion that correct identification in the yield-yield cell requires subjects to have encoded both sign color (a subtle cue) and semantic meaning of the sign, while in the stop-yield cell, subjects need only encode semantic meaning for accurate identification. The crucial comparison is the simple effect within the yield-yield cells, that is, misleading questions vs. accurate questions.

To summarize, if misleading questions impair the accuracy of eyewitness reports primarily because of demand, this should be reflected by a significant interaction between type of question (accurate/misleading) and type of recognition task (yield-yield/stop-yield). This interaction should be due to misled subjects' being less accurate than led subjects only in the stop-yield cell. If, in fact, a similar effect occurs in those cells in which subjects are faced with the yield-yield choice (i.e., a simple effect for the misleading/accuracy factor), this would indicate that the effect of misleading questions is not entirely accounted for by demand characteristics.

\section{METHOD}

\section{Subjects}

Three hundred and thirty-one undergraduate psychology students at the University of Iowa participated in this experiment for partial course credit. Two failed to complete the posttest materials. Subjects were run in groups ranging in size from 15 to 30 .

\section{Materials and Procedures}

Subjects signed up in advance for an experiment labeled "Media Effects." Subjects were told that they would be asked to look at some slides and then to answer some questions that might or might not relate to those slides.

After receiving the instructions and signing informed consent cards, all subjects viewed 29 color slides for approximately $3 \mathrm{sec}$ each (Stage 1). All slides, including those used in the posttest, were projected via a GAF Anscorama 980 slide projector equipped with a 4- to 6-in. Zoom (f:3.5) lens, located approximately $20 \mathrm{ft}$ from the screen.

The slides depict the following narrative. A black car is seen driving down a hill, pausing at a yellow yield sign, and turning right. A red car is encountered half on and half off the road. The rear door on the driver's side is open, and a tire is lying in the middle of the road, blocking the path of the black car. The 
driver of the black car looks at the tire, then looks at the open door of the car, and then looks in the car. He closes the door and then walks over to the tire and picks it up. He rolls it out of the way. The black car drives off.

After viewing the slide show, all subjects received one of two versions of the experimental questionnaire (Stage 2). Each version contained 10 true-false questions about the slide show. Both versions of the experimental questionnaire were identical, except for Question 5. The misleading version of Question 5 read: "The black car had its turn signal on when it passed the stop sign" (true-false). The accurate version of Question 5 used the same wording with the word "yield" substituted for "stop."

After completing the experimental questionnaire, subjects performed $20 \mathrm{~min}$ of filler tasks, including two digit-copying tasks, a coding task, and a set of analogies. After completing the filler tasks, half the subjects were sent out of the experimental room while the other half were shown one of the two forcedchoice recognition tasks (Stage 3 ). This took approximately $45 \mathrm{sec}$, after which those subjects who had been sent out of the room returned to take the other of the two recognition tasks while their cohorts were sent out of the room. Finally, all subjects were brought back into the room, debriefed, and dismissed.

In the forced-choice recognition task, subjects were asked to indicate which of two slides, simultaneously displayed on screens, they had previously seen. Each slide was shown for $30 \mathrm{sec}$. In each posttest, one slide, depicting either a red stop sign or a red yield sign, was pitted against the slide showing a yellow yield sign that had formed a part of the original series. Slide presentation was left-right counterbalanced for both posttests.

\section{RESULTS}

Each subject's accuracy score was a dichotomous variable reflecting whether he or she accurately identified the yellow yield sign (score $=1$ ) or erred by choosing the red stop sign or the red yield sign $($ score $=0)$. This dichotomous variable was analyzed in an analysis of variance having question type (accurate, misleading) and type of recognition task (yield-yield, stop-yield) as between-subjects factors. This analysis of dichotomous data via analysis of variance followed the guidelines specified by Neter and Wasserman (1974). The proportions of subjects in each cell who chose the correct (yellow) yield sign are presented in Table 1, along with the numbers of subjects in each cell. The data indicate that misleading questions do, in fact, impair recognition accuracy in both the yield-yield and stop-yield posttests. This is reflected in the main effect for question type (accurate-misleading), indicating that subjects who received misleading questions (at Stage 2) were significantly less accurate on the recognition test (at Stage 3)

Table 1

Proportions (P) of Subjects in Each Cell Who Chose the Correct Slide, Along With Number (n) of Subjects per Cell

\begin{tabular}{ccccc} 
& \multicolumn{3}{c}{ Question Type } \\
\cline { 2 - 3 } Type of & \multicolumn{2}{c}{ Accurate } & & Misleading \\
\cline { 2 - 3 } \cline { 5 - 6 } Recognition Test & $\mathrm{P}$ & $\mathrm{n}$ & $\mathrm{P}$ & $\mathrm{n}$ \\
\hline Stop-Yield & .926 & 82 & .626 & 83 \\
Yield-Yield & .775 & 80 & .604 & 86 \\
\hline
\end{tabular}

than those receiving accurate questions (at Stage 2) $[F(1,327)=25.42, p<.0001]$. As Table 1 indicates, this effect tended to be more pronounced among subjects exposed to the stop-yield recognition test than among those exposed to the yield-yield test, but this tendency in the data was not reflected in a significant interaction between question type (accurate, misleading) and type of recognition test (yield-yield, stop-yield) $[F(1,327)=1.64, p<.2015]$.

Despite the lack of a significant interaction, this data pattern prompted us to conduct simple effects tests to be certain that question type affected accuracy in the yield-yield condition. This simple effect in the yieldyield cell was, in fact, significant $(Z=2.42, p<.018)$. Here, too, subjects were less accurate when they had responded to a misleading question at Stage 2 of the procedure. Finally, as expected, the accuracy data indicate that the yield-yield test was more difficult than the stop-yield test $[F(1,327)=3.60, p<.06]$.

\section{DISCUSSION}

These data suggest that misled subjects are less likely to give accurate eyewitness reports than nonmisled subjects even when there are few demand features in the reporting situation. In fairness, it appears plausible that demand does contribute to a proportion of the variance created by misleading questions, since the impact of misleading questions tends to be greater in the stop-yield cells. This is not a surprising outcome, since it indicates only that misleading questions will have more impact when subsequent reporting situations contain cues that support the plausibility of the misleading question. The outcome in the yield-yield cell, however, indicated that even when the final reporting situation (i.e., Stage 3 ) does not permit one to accede to at least the most obvious of the demand pressures created by the misleading question in Stage 2, a greater proportion of subjects are inaccurate if they have been previously misled. Apparently, misleading questions can produce some confusion regarding the reporting of event memories.

Although these data suggest that demand is not the sole explanation for the effects that misleading questions have on recall, they do not provide evidence as to the rest of the explanation. Based on the present data alone, one cannot tell whether misled subjects form new memories of the event or whether they are so confused by the misleading information that they resort to guessing. The large variability in the misled cells (in which roughly $60 \%$ of the subjects accurately identify the sign ${ }^{3}$ and $40 \%$ do not) is certainly compatible with the view that misled subjects could have been confused by the misleading questions, but these are hardly conclusive data. Nevertheless, this tentative evidence of variability could be considered congruent with a social influence view. If a misleading question creates the impression 
that others (i.e., the questioner) hold a view of the event that conflicts with the subject's perception, the situation could represent a typical judgmental conflict found in the social influence literature. In this literature, confusion is frequently reported to result from such conflict, with a good deal of variability of responding between subjects (Asch, 1951). Thus, the effects in Table 1 could reflect the fact that some, but not all, subjects are affected by social influence.

Although the present study provides no definitive resolution of such issues of causality, the data do strongly suggest that misleading questions will bias event reporting even when demand characteristics are minimal. While Loftus and her colleagues have provided a number of varied and ingenious demonstrations of this bias, a skeptic could claim these prior effects were mediated by demand. The present experiment may be viewed as a severe test of the question of whether the kind of reporting errors found by Loftus and her associates are totally reducible to demand characteristics. We conclude that they are not. Note that we recognize that some portion of the reporting bias found in prior studies may be due to demand (see above). We also recognize that a skeptic might find procedural reasons to argue that the present findings really do not apply to the specific studies reported by Loftus and her associates. However, even if one is reluctant to view these data as a "vindication" of Loftus' specific studies, these data do indicate that the type of bias Loftus and her associates highlight does occur at a respectable level of significance even when demand features are minimal. Additional research will be needed before we fully understand why misleading questions lead to such bias. However, in the applied setting, that of the eyewitness before the jury, the precise mechanisms by which bias is induced are perhaps less important than the demonstration that witnesses can be, and presumably are, biased by misleading questions.

\section{REFERENCES}

Asch, S. E. Effects of group pressure upon the modification and distortion of judgments. In H. Guetzkow (Ed.), Groups, leadership, and men. Pittsburgh: Carnegie Press, 1951.

LoFtus, E. F. Reconstructing memory: The incredible eyewitness. Psychology Today, December 1974, pp. 116-119.

LofTus, E. F. Eyewitness. Puget Sound, October 1975. (a)
Loftus, E. F. Leading questions and the eyewitness report. Cognitive Psychology, 1975, 7, 560-572. (b)

Loftus, E. F. Shifting human color memory. Memory \& Cognition, 1977, 5, 696-699.

LofTus, E. F. Reconstructive memory processes in eyewitness testimony. In B. D. Sales (Ed.), Perspectives in law and psy. chology. New York: Plenum, 1978.

LofTus, E. F. Eyewitness testimony. Cambridge: Harvard University Press, 1979.

Loftus, E. F., Altman, D., \& Geballe, R. Effects of questioning upon a witness' later recollections. Journal of Police Science and Administration, 1975, 3, 162-165.

Lofrus, E. F., \& Loftus, G. R. On the permanence of stored information in the human brain. American Psychologist, 1980, $35,409-420$.

Loftus, E. F., Miller, D. G., \& Burns, H. J. Semantic integration of verbal information into a visual memory. Journal of Experimental Psychology: Human Learning and Memory, $1978,4,19-31$.

Loftus, E. F., \& Palmer, J. C. Reconstruction of automobile destruction: An example of the interaction between language and memory. Journal of Verbal Learning and Verbal Behavior, 1974, 13, 585-589.

Loftus, E. F., \& ZANNI, G. Eyewitness testimony: The influence of the wording of a question. Bulletin of the Psychonomic Society, 1975, 5, 86-88.

Neter, J., \& Wasserman, W. Linear statistical models. Homewood, Ill: Irwin, 1974.

Sherif, M. A study of some social factors in perception. Archives of Psychology, 1935, 27, No. 187.

Wyer, R. S., \& Carlston, D. E. Social cognition, inference and attribution. Hillsdale, N.J: Erlbaum, 1979.

\section{NOTES}

1. Wyer and Carlston's (1979) recent discussion of social cognition and memory suggests another possible explanation for actual belief change. Leading questions may activate relevant concept nodes (i.e., "smashed"). According to Wyer and Carlston, when a given concept node is activated or engaged, this raises the probability that closely related concepts will be accessed in memory search due to a spread of excitation at least until the original excitation decays.

2. Loftus et al. (1978) counterbalanced whether a stop or a yield sign was used as an initial stimulus. Since they found it made no difference which sign they used, it seemed justifiable to simplify the present design.

3. Error rates were somewhat higher in the Loftus et al. (1978) study. This may be due to the fact that different slides were used in the two studies.

(Received for publication February 16, 1982; revision accepted August 31, 1982.) 